\title{
8. BEGO Medical Anwendertreffen
}

\section{Rund 600 Teilnehmer, 16 hochkarätige Referenten und 2 Varseo 3D-Druck-Systeme als Hauptgewinn - der letzte „Implantology meets CAD/CAM“-Kongress (IMCC) der BEGO brach alle Rekorde der Vorjahre. Im Fokus stand auch diesmal der interdisziplinäre Austausch unter den Teilnehmern und mit den BEGO Experten. Auch zum Expertentreffpunkt am Vortag des Kongresses reisten bereits viele IMCC-Teilnehmer nach Bremen.}

Eröffnet wurde das Kongressprogramm am Samstag, den 14. November 2015 vom geschäftsführenden Gesellschafter Christoph Weiss. Direkt im Anschluss sprach er über das Thema „Miteinander!“. Aktuelle Entwicklungen in der Dentalbranche und Unternehmenswerte, die für ein erfolgreiches wirtschaftliches Handeln von großer

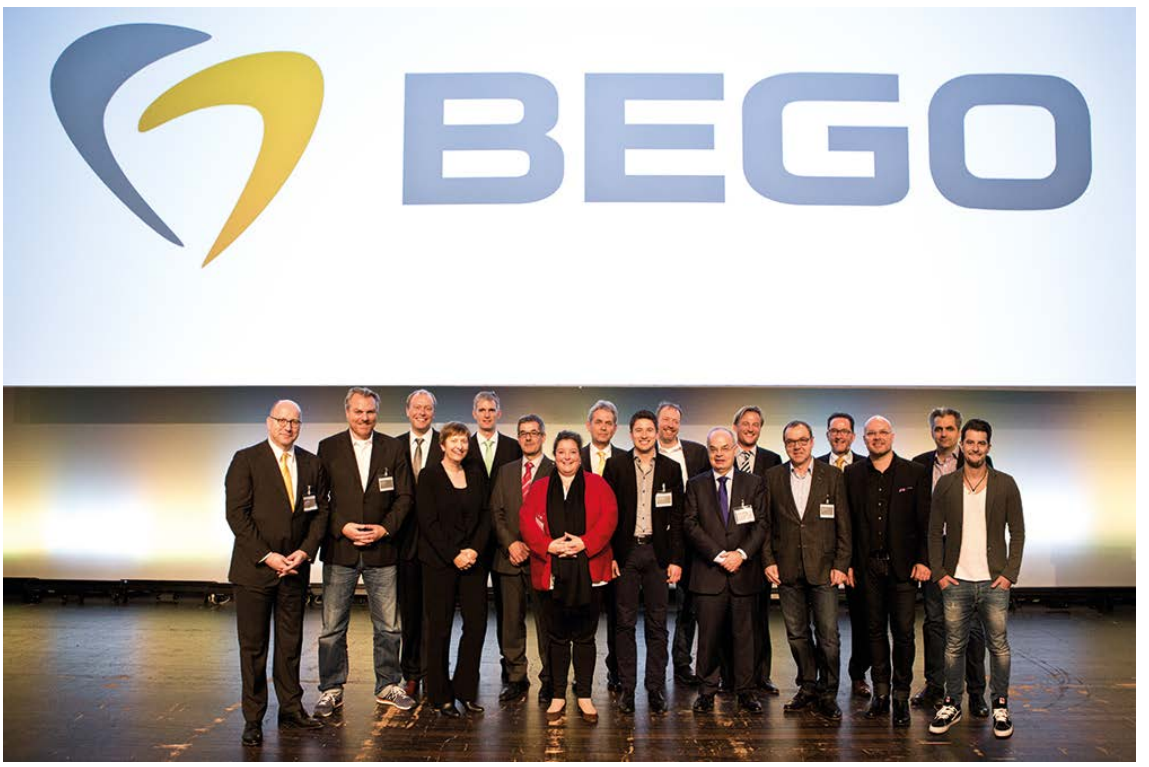

Bedeutung sind, standen im Fokus seines Vortrags. „All unser Tun, ob Zahntechniker, Zahnarzt oder Implantologe - es kommt am Ende des Tages auf den Patienten an und dass wir ihn mit hochwertigen Produkten und Dienstleistungen gut versorgen können“, so Weiss.
Das Thema 3D-Druck stellte nicht nur den Fokus des am Vortag stattfindenden BEGO Expertentreffpunktes dar, sondern auch den des Vortrags von Prof. Constantin von See, Danube Private University, Krems (Österreich). Er sprach vor den Teilnehmern, die aus dem gesamten Bundesgebiet, aber auch aus den Niederlanden und Österreich angereist waren, über „Revolution oder Evolution? 3D-Druck im Dentalbereich“. Später wurden die Vorträge in unterschiedlichen Podien fortgesetzt. Beim 8. BEGO Medical Anwendertreffen standen gewohnt Themen aus der Zahntechnik im Fokus. Der 6. Bremer Implantologietag hielt für die Zahnmediziner und Implantologen ebenso spannende Themen bereit.

Zur Teilnehmergruppe der Zahnmediziner, Implantologen und Zahntechniker, gesellte sich in diesem Jahr auch der dentale Nachwuchs. Die Möglichkeit zu vergünstigten Preisen am Kongress teilzunehmen, wurde von einer Reihe von jungen und engagierten Zahntechnikauszubildenden, Meisterschülern sowie Studenten der Zahnmedizin und -technik genutzt. Am Abend ließen die Teilnehmer die gelungene Veranstaltung im Congress Center Bremen ausklingen. „Über die große Zahl der Teilnehmer freuen wir uns natürlich besonders. Noch wichtiger ist aber das positive Feedback der Teilnehmer welches wir erhalten haben, die die Qualität und die Atmosphäre der Veranstaltung schätzen“, freut sich Weiss zum Abschluss der Veranstaltung.

Nach einer Pressemitteilung der BEGO Bremer Goldschlägerei Wilh. Herbst GmbH \& Co. KG, Bremen www.bego.com 